\section{Fatores que influenciam as relações familiares e sociais de jovens após a gestação}

\author{
Factors affecting young mothers' social and family \\ relations after pregnancy
}

\author{
Factores que afectan las relaciones familiares y \\ sociales de jóvenes después del embarazo
}

1 Universidade Federal do
Piauí, Teresina, Brasil.
Correspondência
T. A. Maranhão
Av. Frei Serafim 2280,
Teresina, PI
64001-020,Brasil.
thatymaranhao@hotmail.com

Abstract

This study aimed to analyze factors affecting social and family relations of young mothers in the two-year postpartum period. This was a crosssectional study of 464 young mothers in Teresina, Piaui State, Brazil, who gave birth during the first four months of 2006 in six maternity hospitals. Data were collected from May to December 2008 after identifying the young women in the maternity hospital records. Multivariate analysis used multinomial logistic regression. Married young women (including those in common-law marriages) were $80 \%$ less likely to have negative relations with their partners. Participants 20 to 22 years of age related 2.4 times better with their mothers than those 17 to 19 years of age. Young women not attending school showed 97\% higher odds of negative changes in relations with friends, and Catholics were 50\% less likely to have worse relations with friends following childbirth. Measures are needed to orient individuals living with young mothers (especially their partners and mothers) concerning the importance of support in this phase of life, particularly encouraging them to stay in school.

Pregnancy; Adolescent; Family Relation; Social Support; Marriage
Thatiana Araújo Maranhão 1 Keila Rejane Oliveira Gomes 1 José Mário Nunes da Silva 1

\section{Resumo}

Objetivou-se analisar fatores intervenientes nas relações sociais e familiares de jovens dois anos pós-parto. Estudo transversal com 464 jovens de Teresina, Piauí, Brasil, que finalizaram uma gravidez no primeiro quadrimestre de 2006, em seis maternidades do município. Dados foram coletados de maio a dezembro de 2008 após identificação das jovens nos registros das maternidades. A análise multivariada se deu por meio de regressão logística multinomial. Jovens com laços conjugais eram $80 \%$ menos propensas a terem relações negativas com o cônjuge. Participantes com idade de 20-22 anos se relacionavam 2,4 vezes melhor com a mãe do que aquelas com idade de 17-19 anos. Jovens que não estudavam tinham 97\% mais chances de mudanças negativas na relação com os amigos e as católicas eram $50 \%$ menos propensas a terem piorado suas relações de amizade após o parto. São necessárias ações orientadoras aos indivíduos que convivem com as jovens mães sobre a importância do apoio neste momento da vida, principalmente o parceiro e a mãe, incentivando-a a manter-se estudando.

Gravidez; Adolescente; Relações Familiares; Apoio Social; Casamento 


\section{Introdução}

A gravidez consiste em fenômeno peculiar ao desenvolvimento humano normal, entretanto, este mesmo fenômeno pode levar a sérias complicações quando ocorre na juventude 1,2. A gestação nesta etapa evolutiva da vida interfere nas representações sociais das jovens, por meio da súbita passagem do papel de filha e ser dependente para o papel de mãe e provedora. Este conflito deve-se, em muitos casos, ao despreparo físico, emocional, social e econômico que comprometem o pleno exercer das funções maternas caso não haja o redimensionamento da vida da jovem e das pessoas que com ela convivem para se adaptarem ao acontecimento ${ }^{3}$.

É enfatizada a necessidade de se ressignificar o sentido da maternidade na juventude, sendo as percepções quanto a este fato variáveis conforme as circunstâncias nas quais a gravidez ocorre. Muitas vezes a gestação na juventude é inicialmente vista como um acontecimento problemático, gerador de frustrações e insegurança para muitas jovens e suas famílias, mas, para algumas, traduz o produto do desejo de ser mãe ${ }^{4}$. De forma contrária, quando não há a aceitação da gravidez pelos indivíduos que convivem com a jovem, torna-se comum a violência intrafamiliar, não só de caráter físico, mas também psicológico, social e emocional, podendo levar ao abandono ou à imposição do abortamento sob condições muitas vezes precárias 5,6.

Nesse sentido, o apoio e a compreensão às jovens advindos da família, bem como da sociedade em geral são atitudes de extrema importância para proporcionar o conforto psicológico necessário ao seu bem-estar 7. O apoio social é um processo dinâmico e complexo que consiste em todo suporte provido pelo núcleo familiar ou pelos amigos no sentido de fazer com que a pessoa apoiada se sinta cuidada, amparada, compreendida e assistida em suas necessidades, de modo que ela seja capaz de enfrentar seus problemas de modo eficaz 8,9.

No caso da gravidez, inesperada ou não, entre mulheres jovens, os mecanismos de apoio são geralmente procurados no companheiro, entre os membros da família, especialmente os pais, e nos contatos sociais 9. Assim, para que haja o provimento satisfatório desse apoio torna-se imprescindível o estabelecimento de relações positivas entre a jovem e as pessoas à sua volta 10 .

O bom relacionamento existente entre a jovem e sua família possui o poder de suprir a dependência que muitas possuem referente tanto ao suporte emocional, como ao status financeiro e os cuidados com a criança. Além disso, o bemestar propiciado por estas boas relações evita ansiedade e problemas psicológicos 10 . O relacionamento conflituoso entre a jovem e o pai da criança também reflete diretamente no bem-estar dela e do seu filho, constituindo-se importante fonte de estresse. O relacionamento conjugal negativo pode exacerbar episódios depressivos maternos 11, bem como interferir no desenvolvimento físico e mental de crianças que convivem em lares conturbados 12 .

Além da família e do companheiro, a jovem que engravida também possui a tendência de buscar apoio junto aos seus amigos. Entretanto, nem sempre ela recebe esse suporte, sofrendo muitas vezes com o preconceito na escola e nos ambientes que frequenta, por estar grávida 13 . Quando ela se casa ou torna-se mãe, o relacionamento com os amigos também pode ficar comprometido tendo em vista que passa a existir uma dicotomia entre o seu modo de viver e o de suas amigas que não passaram pelas mesmas experiências que ela até então 14 .

Em face do exposto, percebe-se a importância do estabelecimento de relacionamentos conjugais, familiares e sociais positivos para a jovem que passou pela experiência de uma gestação. Nessa perspectiva, o presente estudo objetivou analisar os fatores que interferem nos relacionamentos sociais e familiares de jovens, dois anos após a finalização de uma gravidez.

\section{Métodos}

Trata-se de estudo transversal, recorte de um projeto de pesquisa mais amplo intitulado Gravidez na Adolescência: Fatores Preditores da Reincidência 15 . Os dados foram coletados de maio a dezembro de 2008, entre jovens residentes na área urbana do Município de Teresina, Piauí, Brasil, que finalizaram uma gravidez no primeiro quadrimestre de 2006, em seis maternidade da cidade, sendo que cinco dessas instituições eram públicas e uma privada. Ressalta-se que na época em que finalizaram a gestação as jovens tinham idade entre 15 e 19 anos.

Tendo em vista que o projeto maior se refere à reincidência da gravidez na adolescência, procedeu-se à busca retrospectiva das jovens após dois anos do término da gestação finalizada em 2006. Utilizou-se como parâmetro o intervalo de dois anos desde a última coleta de dados devido ser este o intervalo intergestacional mínimo ideal quando a primeira gravidez resultou em feto vivo, segundo preconizado pela Organização Mundial da Saúde 16.

Uma vez que seriam incluídas no estudo todas as formas de resolução da gravidez e que algumas dessas formas não são conhecidas em 
toda a sua dimensão devido a sua subnotificação como, por exemplo, o aborto, seria inviável o cálculo da amostra probabilística. Nessa perspectiva, tendo em vista esta limitação, optou-se pela amostragem acidental constituída pelos elementos que são possíveis de se localizar em um período de tempo estipulado 17.

Iniciou-se a localização das jovens por meio da identificação delas nos registros das instituições participantes do estudo. Posteriormente, procedeu-se ao contato telefônico para convite às jovens a participarem da pesquisa. Quando não era possível o contato telefônico devido à ausência deste dado nos registros, mas o endereço estava disponível, duas entrevistadoras iam ao endereço da residência delas. Caso aceitassem participar do estudo, o formulário semiestruturado, pré-codificado e pré-testado era aplicado. Nos casos em que havia algum impedimento para a entrevista naquele momento, números de telefones eram solicitados para posterior contato com vistas a agendar nova data e horário para visita das entrevistadoras.

As jovens não localizadas foram listadas para que, posteriormente, fosse solicitado às enfermeiras dos serviços de atenção básica que atuavam nas equipes correspondentes à área onde supostamente residia a jovem buscada, tentassem encontrar o endereço correto destes casos junto ao agente comunitário de saúde. Este procedimento foi realizado quando os vizinhos do endereço inicial da jovem informavam apenas o bairro para onde ela havia se mudado, sem dispor do novo endereço.

Devido ao procedimento metodológico empregado, no qual eram feitas buscas ativas dos casos nos bancos de dados das maternidades dois anos após o seu registro, eram esperados que muitos destes não fossem localizados. Outra limitação da amostra foi a inacessibilidade aos casos de curetagem provenientes do estabelecimento particular, em virtude do sigilo que os envolviam. Dessa forma, das 632 jovens localizadas nos registros das maternidades, 464 foram entrevistadas e 168 foram considerados casos perdidos. Estas perdas ocorreram devido a não localização de 164 jovens, três recusas em participar da pesquisa e à ocorrência de um óbito materno.

Os dados foram digitados, inicialmente, no software Epi Info versão 6.04d (Centers for Disease Control and Prevention, Atlanta, Estados Unidos), em dois bancos de dados para que fossem checados eventuais erros de digitação e feitas as devidas correções. A análise estatística foi feita utilizando-se o software IBM SPSS versão 18.0 para Windows (IBM Corp., Armonk, Estados Unidos). A análise univariada se deu por meio de estatística descritiva das variáveis relativas às características sociodemográficas e psicossociais. Para a análise bivariada dos dados foi empregado o teste qui-quadrado de Pearson $\left(\chi^{2}\right)$ com vistas a identificar associações entre as características sociodemográficas das jovens (variáveis independentes) e a percepção delas sobre as modificações ocorridas nos relacionamentos com o companheiro, pai, mãe e amigos dois anos após a resolução da gravidez (variáveis dependentes). Para tanto, consideraram-se estatisticamente significativos valores de $\mathrm{p} \leq 0,0518$.

Foram recodificadas duas variáveis independentes para permitirem o cálculo da análise multivariada. Uma foi a variável "estado conjugal", que anteriormente continha cinco alternativas de múltipla escolha e foi recodificada em apenas nas alternativas "mantém laços conjugais" e "não mantém laços conjugais”. A categoria "mantém laços conjugais" passou a incluir todas as jovens casadas, as que estavam em união consensual e ainda aquelas que não residiam com o companheiro, mas que referiram manter um relacionamento afetivo com ele. As jovens que "não mantinham laços conjugais" são aquelas que referiram estar solteiras no momento da entrevista, incluindo-se também as divorciadas e as viúvas. A segunda variável recategorizada foi "Religião", a qual tinha quatro categorias e passou a ter apenas as categorias "Católica" e "Não católica". As jovens "não católicas" são todas aquelas que seguiam outras religiões e as sem religião.

A análise multivariada foi feita por meio de regressão logística multinomial (RLM), a qual foi utilizada para obter estimativas de odds ratio (OR) e intervalos de 95\% de confiança (IC95\%) (método de Woolf) ajustados para variáveis de confusão 19 . Esse método permite o cálculo de OR considerando-se uma variável dependente com mais de duas categorias. Nesse caso, cada categoria é comparada à categoria de referência num único processamento.

A análise foi feita pela comparação entre as jovens que não observaram modificações nos relacionamentos (categoria de referência) com as jovens que relataram mudanças positivas e negativas em seus relacionamentos com o companheiro, pai, mãe e amigos.

O critério para a inclusão de variáveis no modelo de RLM foi a constatação de associações estatísticas significativas entre os relacionamentos das jovens e as variáveis independentes na análise bivariada, tendo-se como referência um valor de $\mathrm{p}<0,2020$. Na análise multivariada, a hipótese de nulidade foi rejeitada quando o valor de $\mathrm{p}<0,05$.

$\mathrm{O}$ teste do pressuposto de multicolinearidade exigido para a RLM foi realizado pelo VIF (variance-inflation factor), o qual foi calculado 
por meio de regressão linear múltipla. Adotou-se como ponto de corte para a multicolinearidade um $\operatorname{VIF} \geq 4$. Entretanto, o teste não mostrou evidência de multicolinearidade entre as variáveis independentes incluídas no modelo 21.

Visando cumprir todos os preceitos éticos e legais das pesquisas que envolvem seres humanos, segundo determinações da Declaração de Helsinki e da Resolução no 196/96 do Conselho Nacional de Saúde, o projeto que originou este estudo foi aprovado pelo Comitê de Ética em Pesquisa (CEP) da Universidade Federal do Piauí (UFPI), sob CAAE no 0056.0.045.000-08. A todas as participantes dessa pesquisa foi solicitada a assinatura do termo de consentimento livre e esclarecido (TCLE). Para as jovens menores de 18 anos, a assinatura do TCLE foi feita por seu responsável legal. Além disso, foi requerida permissão de acesso aos dados das pacientes ao gestor da instituição estadual, à Fundação Municipal de Saúde, gestora do Sistema Único de Saúde (SUS) em Teresina, e à direção do estabelecimento privado.

\section{Resultados}

A Tabela 1 mostra as mudanças referidas pelas jovens mães no seu relacionamento com o parceiro, pai, mãe e amigos dois anos após a resolução da gravidez. Constatou-se que as jovens referiram mudanças predominantemente positivas no seu relacionamento conjugal (39,9\%), ao passo que, $62,1 \%, 51,8 \%$ e $48,7 \%$ das entrevistadas referiram a ausência de modificações nos relacionamentos com o pai, mãe e amigos após a resolução da gravidez, respectivamente.

Dentre as jovens que observaram modificações no relacionamento familiar dois anos após a gestação, verificou-se que das mudanças ocorridas nas relações com o pai $(24,9 \%)$ e com a mãe $(38,1 \%)$ sobressaíram-se as positivas. Entretanto, foram observadas modificações predominantemente negativas nas relações de amizade $(37,1 \%)$ das participantes que verificaram mudanças neste tipo de relacionamento.

Das 464 jovens participantes deste estudo, $69,8 \%$ eram da faixa etária de $20-22$ anos, $69,6 \%$ já não estudavam, 76,7\% mantinham laços conjugais, $72,2 \%$ não trabalhavam, $50 \%$ possuíam renda familiar mensal de até um salário mínimo e $81,3 \%$ referiram ser da religião católica (Tabelas 2, 3 e 4).

A Tabela 2 evidencia a associação estatística significativa entre as mudanças ocorridas no relacionamento com o companheiro dois anos após a gestação e o fato de manter ou não um relacionamento conjugal (valor de $\mathrm{p} \leq 0,05$ ). Entretanto, não houve associação estatística significativa entre as demais variáveis sociodemográficas testadas e as modificações percebidas pela jovem no seu relacionamento conjugal.

\begin{tabular}{lcc}
\hline Relacionamentos & $\mathbf{n}$ & $\%$ \\
\hline Mudanças ocorridas no relacionamento com o companheiro & 464 & 100,0 \\
Positivo & 185 & 39,9 \\
Não houve mudanças & 146 & 31,5 \\
Negativo & 133 & 28,6 \\
Mudanças ocorridas no relacionamento com o pai & 338 & 100,0 \\
Positivo & 84 & 24,9 \\
Não houve mudanças & 210 & 62,1 \\
Negativo & 44 & 13,0 \\
Mudanças ocorridas no relacionamento com a mãe & 436 & 100,0 \\
Positivo & 166 & 38,1 \\
Não houve mudanças & 226 & 51,8 \\
Negativo & 44 & 10,1 \\
Mudanças ocorridas no relacionamento com os amigos & 463 & 100,0 \\
Positivo & 66 & 14,3 \\
Não houve mudanças & 225 & 48,6
\end{tabular}


Tabela 2

Variáveis sociodemográficas e mudanças ocorridas no relacionamento com o companheiro dois anos após a gestação. Teresina, Piauí, Brasil, 2008.

\begin{tabular}{|c|c|c|c|c|c|c|c|c|c|c|c|}
\hline \multirow[t]{3}{*}{ Variáveis sociodemográficas } & \multirow[t]{3}{*}{$\mathbf{n}$} & \multirow[t]{3}{*}{$\%$} & \multicolumn{9}{|c|}{ Mudanças no relacionamento com companheiro dois anos após a gestação } \\
\hline & & & \multicolumn{2}{|c|}{ Positivo } & \multicolumn{2}{|c|}{ Não se modificou } & \multicolumn{2}{|c|}{ Negativo } & \multicolumn{2}{|c|}{ Total } & \multirow[t]{2}{*}{ Valor de $p$ * } \\
\hline & & & $\mathbf{n}$ & $\%$ & $\mathbf{n}$ & $\%$ & $\mathbf{n}$ & $\%$ & $\mathbf{n}$ & $\%$ & \\
\hline \multicolumn{12}{|l|}{ Faixa etária (anos) } \\
\hline $17-19$ & 140 & 30,2 & 61 & 43,6 & 42 & 30,0 & 37 & 26,4 & 140 & 100,0 & 0,556 \\
\hline $20-22$ & 324 & 69,8 & 124 & 38,3 & 104 & 32,1 & 96 & 29,6 & 324 & 100,0 & \\
\hline \multicolumn{12}{|l|}{ Estado conjugal } \\
\hline Mantém laços & 356 & 76,7 & 171 & 48,0 & 119 & 33,4 & 66 & 18,5 & 356 & 100,0 & $<0,001$ \\
\hline Não mantém laços & 108 & 23,3 & 14 & 13,0 & 27 & 25,0 & 67 & 62,0 & 108 & 100,0 & \\
\hline \multicolumn{12}{|l|}{ Estuda } \\
\hline Não & 323 & 69,6 & 139 & 43,0 & 101 & 31,3 & 83 & 25,7 & 323 & 100,0 & 0,510 \\
\hline Sim & 141 & 30,4 & 46 & 32,6 & 45 & 31,9 & 50 & 35,5 & 141 & 100,0 & \\
\hline \multicolumn{12}{|l|}{ Escolaridade (anos de estudo) } \\
\hline$\leq 8$ & 222 & 47,8 & 94 & 42,3 & 65 & 29,3 & 63 & 28,4 & 222 & 100,0 & 0,519 \\
\hline$>8$ & 242 & 52,2 & 91 & 37,6 & 81 & 33,5 & 70 & 28,9 & 242 & 100,0 & \\
\hline \multicolumn{12}{|l|}{ Trabalha } \\
\hline Não & 335 & 72,2 & 139 & 41,5 & 107 & 31,9 & 89 & 26,6 & 335 & 100,0 & 0,255 \\
\hline Sim & 129 & 27,8 & 46 & 35,7 & 39 & 30,2 & 44 & 34,1 & 129 & 100,0 & \\
\hline \multicolumn{12}{|l|}{ Renda (salário mínimo) } \\
\hline Até 1 & 232 & 50,0 & 90 & 38,8 & 74 & 31,9 & 68 & 29,3 & 232 & 100,0 & 0,891 \\
\hline$>1$ & 232 & 50,0 & 95 & 40,9 & 72 & 31,0 & 65 & 28,0 & 232 & 100,0 & \\
\hline \multicolumn{12}{|l|}{ Religião } \\
\hline Católica & 377 & 81,3 & 153 & 40,6 & 120 & 31,8 & 104 & 27,6 & 377 & 100,0 & 0,561 \\
\hline Não católica & 87 & 18,7 & 32 & 36,8 & 26 & 29,9 & 29 & 33,3 & 87 & 100,0 & \\
\hline
\end{tabular}

* Teste qui-quadrado de Pearson.

Os dados apresentados na Tabela 3 mostram que houve associação estatística significativa entre as modificações observadas pela jovem no relacionamento dela com a sua mãe e a sua faixa-etária (valor de $\mathrm{p} \leq 0,05$ ). Para as demais variáveis sociodemográficas, não se observaram associações.

Na Tabela 4 é mostrada a significância estatística significativa entre as mudanças percebidas pela jovem no seu relacionamento com os amigos e o fato de ela estudar, a sua escolaridade e a sua religião (valor de $\mathrm{p} \leq 0,05$ ). Todavia, não foram verificadas associações entre as demais variáveis sociodemográficas e a variável dependente.

A Tabela 5 mostra as variáveis sociodemográficas que interferem no relacionamento da jovem com o seu companheiro, mãe e amigos. Observou-se associação estatística significativa (valor de $\mathrm{p}<0,05$ ) entre o fato de a jovem manter ou não laços conjugais e as mudanças ocorridas no relacionamento com o companheiro. A análise do modelo de regressão multinomial demonstra que jovens com laços conjugais com um companheiro estão 2,8 vezes mais propensas a terem mudanças positivas em seus relacionamentos com o parceiro e $80 \%$ menos propensas a terem mudanças negativas nestes relacionamentos do que as que referiram não manter laços conjugais com um companheiro.

Jovens na faixa-etária de 20-22 anos possuem 2,4 mais chances de ter relacionamento positivo com a mãe delas quando comparadas às adolescentes na faixa-etária de 17-19 anos (valor de $\mathrm{p}$ $<0,05)$. Não foi detectada qualquer associação entre as variáveis independentes e as variações no relacionamento entre as jovens e seus pais dois anos após a resolução da gravidez em 2006.

No que diz respeito às relações de amizade, constatou-se significância estatística na associação entre as variáveis sociodemográficas "estudar" e "religião" e o relacionamento com os amigos (valor de $\mathrm{p}<0,05$ ). O modelo de regressão multinomial mostra que as jovens que não estudam estão $97 \%$ mais propensas a terem alterações negativas em seus relacionamentos com os amigos em comparação às jovens que estudam. Ademais, as entrevistadas que referiram ser católicas eram $50 \%$ menos propensas a terem seus 
Variáveis sociodemográficas e mudanças ocorridas no relacionamento com a mãe dois anos após a gestação. Teresina, Piauí, Brasil, 2008.

\begin{tabular}{|c|c|c|c|c|c|c|c|c|c|c|c|}
\hline \multirow[t]{3}{*}{ Variáveis sociodemográficas } & \multirow[t]{3}{*}{$\mathrm{n}$} & \multirow[t]{3}{*}{$\%$} & \multicolumn{9}{|c|}{ Mudanças no relacionamento com a mãe dois anos após a gestação } \\
\hline & & & \multicolumn{2}{|c|}{ Positivo } & \multicolumn{2}{|c|}{ Não se modificou } & \multicolumn{2}{|c|}{ Negativo } & \multicolumn{2}{|c|}{ Total } & \multirow[t]{2}{*}{ Valor de $p$} \\
\hline & & & $\mathbf{n}$ & $\%$ & $\mathbf{n}$ & $\%$ & $\mathbf{n}$ & $\%$ & $\mathbf{n}$ & $\%$ & \\
\hline \multicolumn{12}{|l|}{ Faixa etária (anos) } \\
\hline $17-19$ & 140 & 30,2 & 69 & 50,4 & 54 & 39,4 & 14 & 10,2 & 137 & 100,0 & 0,001 \\
\hline $20-22$ & 324 & 69,8 & 97 & 32,4 & 172 & 57,5 & 30 & 10,0 & 299 & 100,0 & \\
\hline \multicolumn{12}{|l|}{ Estado conjugal } \\
\hline Mantém laços & 356 & 76,7 & 127 & 38,1 & 175 & 52,6 & 31 & 9,3 & 333 & 100,0 & 0,608 \\
\hline Não mantém laços & 108 & 23,3 & 39 & 37,9 & 51 & 49,5 & 13 & 12,6 & 103 & 100,0 & \\
\hline \multicolumn{12}{|l|}{ Estuda } \\
\hline Não & 323 & 69,6 & 110 & 36,7 & 160 & 53,3 & 30 & 10,0 & 300 & 100,0 & 0,630 \\
\hline Sim & 141 & 30,4 & 56 & 41,2 & 66 & 48,5 & 14 & 10,3 & 136 & 100,0 & \\
\hline \multicolumn{12}{|l|}{ Escolaridade (anos de estudo) } \\
\hline$\leq 8$ & 222 & 47,8 & 71 & 34,0 & 112 & 53,6 & 26 & 12,4 & 209 & 100,0 & 0,122 \\
\hline$>8$ & 242 & 52,2 & 95 & 41,9 & 114 & 50,2 & 18 & 7,9 & 227 & 100,0 & \\
\hline \multicolumn{12}{|l|}{ Trabalha } \\
\hline Não & 335 & 72,2 & 117 & 36,8 & 166 & 52,2 & 35 & 11,0 & 318 & 100,0 & 0,470 \\
\hline $\operatorname{Sim}$ & 129 & 27,8 & 49 & 41,5 & 60 & 50,8 & 9 & 7,6 & 118 & 100,0 & \\
\hline \multicolumn{12}{|l|}{ Renda (salário mínimo) } \\
\hline Até 1 & 232 & 50,0 & 75 & 34,2 & 121 & 55,3 & 23 & 10,5 & 219 & 100,0 & 0,252 \\
\hline$>1$ & 232 & 50,0 & 91 & 41,9 & 105 & 48,4 & 21 & 9,7 & 217 & 100,0 & \\
\hline \multicolumn{12}{|l|}{ Religião } \\
\hline Católica & 377 & 81,3 & 131 & 36,8 & 186 & 52,2 & 39 & 11,0 & 356 & 100,0 & 0,313 \\
\hline Não católica & 87 & 18,7 & 35 & 43,8 & 40 & 50,0 & 5 & 6,3 & 80 & 100,0 & \\
\hline
\end{tabular}

* Teste qui-quadrado de Pearson.

relacionamentos com os amigos mudado negativamente em relação às jovens que não seguiam a religião católica.

\section{Discussão}

Das participantes que observaram mudanças no relacionamento com o companheiro e a família dois anos após a resolução da gravidez, parcela expressiva referiu que as modificações ocorridas nestes relacionamentos foram positivas. Pesquisas demonstraram que pode haver o fortalecimento da união e solidez do relacionamento conjugal durante e após a gravidez, com o companheiro passando a assumir postura mais protetora com a jovem e seu filho e oferecendo ajuda na execução das tarefas domésticas 22,23. Contudo, estudo realizado com casais norteamericanos demonstrou que a percepção positiva do relacionamento conjugal pode variar ao longo dos anos após o nascimento da criança, sendo esta visão baseada no nível de suporte recebido do cônjuge. Assim, evidenciou-se que o nível de apoio tende a ser alto no pós-parto, diminuindo gradualmente no decorrer de cinco anos 24 .

Tem sido mostrado que a presença do companheiro garante o apoio não somente econômico, mas também psicológico. A ausência do pai da criança no domicílio está relacionada à baixa adesão ao pré-natal entre as gestantes 25 , bem como ao parto prematuro e nascimento de crianças de baixo peso e pequenas para a idade gestacional 26 . Em contraste, a presença e o apoio efetivo do parceiro estão relacionados à maior adesão ao aleitamento, à redução do estresse materno e ao melhor desenvolvimento psicossocial da criança 27,28.

Pesquisa sobre as reações da família frente à gravidez na adolescência mostrou que após o primeiro momento de angústia e crise familiar houve o acolhimento da adolescente grávida. As relações intrafamiliares após o nascimento da criança foram marcadas pelo estabelecimento de alianças e de suporte da sua rede social com apoio financeiro e afetivo das famílias de origem 29 . 
Tabela 4

Variáveis sociodemográficas e mudanças ocorridas no relacionamento com os amigos dois anos após a gestação. Teresina, Piauí, Brasil, 2008.

\begin{tabular}{|c|c|c|c|c|c|c|c|c|c|c|c|}
\hline \multirow[t]{3}{*}{ Variáveis sociodemográficas } & \multirow[t]{3}{*}{ n } & \multirow[t]{3}{*}{$\%$} & \multicolumn{9}{|c|}{ Mudanças no relacionamento com os amigos dois anos após a gestação } \\
\hline & & & \multicolumn{2}{|c|}{ Positivo } & \multicolumn{2}{|c|}{ Não se modificou } & \multicolumn{2}{|c|}{ Negativo } & \multicolumn{2}{|c|}{ Total } & \multirow[t]{2}{*}{ Valor de $p$ * } \\
\hline & & & $\mathrm{n}$ & $\%$ & $\mathrm{n}$ & $\%$ & n & $\%$ & $\mathbf{n}$ & $\%$ & \\
\hline \multicolumn{12}{|l|}{ Faixa etária (anos) } \\
\hline $17-19$ & 140 & 30,2 & 27 & 19,3 & 67 & 47,9 & 46 & 32,9 & 140 & 100,0 & 0,101 \\
\hline $20-22$ & 324 & 69,8 & 39 & 12,1 & 158 & 48,9 & 126 & 39,0 & 323 & 100,0 & \\
\hline \multicolumn{12}{|l|}{ Estado conjugal } \\
\hline Mantém laços & 356 & 76,7 & 50 & 14,1 & 164 & 46,2 & 141 & 39,7 & 355 & 100,0 & 0,103 \\
\hline Não mantém laços & 108 & 23,3 & 16 & 14,8 & 61 & 56,5 & 31 & 28,7 & 108 & 100,0 & \\
\hline \multicolumn{12}{|l|}{ Estuda } \\
\hline Não & 323 & 69,6 & 46 & 14,3 & 143 & 44,4 & 133 & 41,3 & 322 & 100,0 & 0,013 \\
\hline Sim & 141 & 30,4 & 20 & 14,2 & 82 & 58,2 & 39 & 27,7 & 141 & 100,0 & \\
\hline \multicolumn{12}{|l|}{ Escolaridade (anos de estudo) } \\
\hline$\leq 8$ & 222 & 47,8 & 38 & 17,2 & 95 & 43,0 & 88 & 39,8 & 221 & 100,0 & 0,047 \\
\hline$>8$ & 242 & 52,2 & 28 & 11,6 & 130 & 53,7 & 84 & 34,7 & 242 & 100,0 & \\
\hline \multicolumn{12}{|l|}{ Trabalha } \\
\hline Não & 335 & 72,2 & 44 & 13,2 & 161 & 48,2 & 129 & 38,6 & 334 & 100,0 & 0,423 \\
\hline $\operatorname{Sim}$ & 129 & 27,8 & 22 & 17,1 & 64 & 49,6 & 43 & 33,3 & 129 & 100,0 & \\
\hline \multicolumn{12}{|l|}{ Renda (salário mínimo) } \\
\hline Até 1 & 232 & 50,0 & 36 & 15,6 & 100 & 43,3 & 95 & 41,1 & 231 & 100,0 & 0,074 \\
\hline$>1$ & 232 & 50,0 & 30 & 12,9 & 125 & 53,9 & 77 & 33,2 & 232 & 100,0 & \\
\hline \multicolumn{12}{|l|}{ Religião } \\
\hline Católica & 377 & 81,3 & 55 & 14,6 & 192 & 51,1 & 129 & 34,3 & 376 & 100,0 & 0,029 \\
\hline Não católica & 87 & 18,7 & 11 & 12,6 & 33 & 37,9 & 43 & 49,4 & 87 & 100,0 & \\
\hline
\end{tabular}

* Teste qui-quadrado de Pearson.

\begin{tabular}{|c|c|c|c|c|}
\hline & \multicolumn{2}{|c|}{ Positiva * } & \multicolumn{2}{|c|}{ Negativa * } \\
\hline & OR (IC95\%) & Valor de $p$ & OR (IC95\%) & Valor de $p$ \\
\hline \multicolumn{5}{|c|}{ Relacionamento com o companheiro } \\
\hline \multicolumn{5}{|l|}{ Estado conjugal } \\
\hline Não mantém laços & 1,0 & 0,004 & 1,0 & $<0,001$ \\
\hline Mantém laços & $2,8(1,4-5,5)$ & & $0,2(0,1-0,4)$ & \\
\hline \multicolumn{5}{|l|}{ Relacionamento com a mãe } \\
\hline \multicolumn{5}{|l|}{ Faixa etária (anos) } \\
\hline $17-19$ & 1,0 & $<0,001$ & 1,0 & 0,422 \\
\hline $20-22$ & $2,4(1,5-3,8)$ & & $1,3(0,6-2,8)$ & \\
\hline \multicolumn{5}{|c|}{ Relacionamento com os amigos } \\
\hline \multicolumn{5}{|l|}{ Estuda } \\
\hline Sim & 1,0 & 0,504 & 1,0 & 0,003 \\
\hline Não & $1,2(0,6-2,3)$ & & $1,97(1,3-3,1)$ & \\
\hline \multicolumn{5}{|l|}{ Religião } \\
\hline Não católica & 1,0 & 0,683 & 1,0 & 0,010 \\
\hline Católica & $0,9(0,4-1,8)$ & & $0,5(0,3-0,9)$ & \\
\hline
\end{tabular}

IC95\%: intervalo de 95\% de confiança, ajustado para todas as variáveis incluídas no modelo; OR: odds ratio.

* Em relação a categoria não se modificou. 
Em especial, o suporte da mãe da jovem constitui-se atitude de fundamental relevância, pois as responsabilidades com os filhos ainda recaem, em sua maior parte, sobre a mulher. Assim, torna-se comum dentro da família a constituição de redes femininas de apoio para ajudar a cuidar das crianças, sendo os adultos, principalmente as avós, as maiores envolvidas no sustento e cuidado dos seus netos 28,30 . O cuidado e apoio propiciado à jovem por sua mãe pode fornecer sentimentos de maior segurança, assim como maior confiança durante o desenvolvimento das funções maternas, promovendo a melhor adaptação da jovem a nova condição de mãe com o fortalecimento dos vínculos familiares e a retomada dos projetos de vida 31 .

Das jovens que perceberam mudanças no relacionamento com os amigos, a maioria referiu modificações negativas nas relações de amizade dois anos após a gestação. Jovens que se unem conjugalmente e passam a assumir as responsabilidades do seu próprio núcleo familiar, como as atividades domésticas e o trabalho fora do lar, possuem alguma limitação para manter sua rede social ${ }^{32}$. Esta limitação ocorre como consequência do surgimento de novas prioridades que promovem sua organização familiar, uma vez que muitas saem da casa dos pais e passam a dividir as despesas com o cônjuge, não restando tempo para a vida social. Quando a jovem engravida e tem filhos, essa tendência se agrava, pois além dos encargos inerentes à função de dona-de-casa, os cuidados com o filho exigem a disponibilidade de tempo adicional 33 .

Demonstrou-se que o estado conjugal da jovem apresenta forte influência sobre as mudanças ocorridas no relacionamento dela com o seu companheiro dois anos pós-parto. Isso mostra que quando a jovem mantém laços conjugais, as relações com o parceiro tendem a ser positivas, mesmo que eles não morem juntos, visto que nem sempre a situação financeira do casal permite que eles tenham sua própria moradia. Por outro lado, há maior propensão para o estabelecimento de relações negativas com o pai da criança quando a jovem não mantém laços conjugais com um companheiro. Nessa perspectiva, presume-se que o nascimento da criança contribuiu para maior harmonia na convivência entre as jovens e seus parceiros. Entretanto, tem sido mostrado que relações conjugais entre jovens são marcadas por imaturidade emocional e limitação da capacidade em resolver divergências, o que exacerba conflitos conjugais e torna as relações instáveis, embora esses estudos não considerem o fato de o casal ter ou não filhos 33,34 .

A faixa-etária da jovem apresentou-se significativamente associada às mudanças ocorridas no relacionamento com a mãe dela, sendo que as jovens com idade de 20-22 anos apresentaram maior propensão de se relacionarem melhor com a mãe dois anos após a gestação, quando comparadas as adolescentes com idade de 17-19 anos.

As reações familiares diante da maternidade na adolescência fazem emergir conflitos familiares devido à interrupção abrupta dos projetos de vida que a família planejava para a jovem. As relações instáveis devem-se principalmente à ausência de relações conjugais mais sólidas, dependência financeira da família e à evasão escolar tanto durante a gravidez como após o nascimento do filho 23,29. Entretanto, foi evidenciado que as dificuldades iniciais de aceitação da maternidade na adolescência são gradualmente substituídas por maior aceitação e apoio, especialmente por parte da mãe da jovem 35 . Nesse sentido, empreende-se que há maior aceitação da gravidez e da criança pela família e, portanto, o estabelecimento de relações familiares mais positivas, quando as jovens possuem maior maturidade fisiológica e emocional, estabilidade conjugal e independência financeira, condições essas mais prováveis de ocorrer entre as jovens mais velhas, mesmo que não concomitantemente 36 .

Alguns estudos mostraram resultados contrários aos desta investigação em que as adolescentes tendem a ser mais próximas à figura materna após o parto. A inexperiência e dependência da jovem a força a buscar o apoio de sua mãe para aprender sobre os cuidados com o filho e sentir-se ela mesma cuidada, acolhida e protegida. O suporte materno possibilita ainda à jovem a construção de habilidades para lidar com os novos desafios que se estabelecem no interior dos relacionamentos conjugais e familiares como consequência da gestação, além de representar refúgio para os momentos de insegurança e indecisão. Assim, elas tendem a perceber a figura materna como a principal fonte de apoio social, independentemente da aceitação ou não da gravidez ou de residirem juntas 9,37.

Estudar/frequentar uma escola mostrou-se como fator que influencia positivamente o relacionamento com os amigos, visto que as participantes que estudavam apresentavam menos chances de referir relações de amizade negativas quando comparadas as que não frequentavam o ambiente escolar.

Pesquisa sobre a maternidade entre adolescentes constatou que o empobrecimento dos contatos de amizade estava diretamente associado à evasão escolar e ao fato de não frequentar espaços direcionados ao lazer. A pesquisa enfatizou ainda que eram as demandas exigidas no cuidado com os filhos que as mantinham fora da escola e de atividades culturais, de lazer e 
esporte e, portanto, longe de uma rede de contatos sociais 38 .

Adolescentes recentemente grávidas que frequentam a escola são mais propensas a ter autoestima mais elevada que aquelas que não estudam 39. Este dado é particularmente relevante, tendo em vista que jovens que possuem baixa autoestima relacionam-se de forma pior com os colegas de turma e professores, em comparação aos jovens que apresentam autoestima mais elevada 40.

Foi observado que as jovens católicas eram mais propensas a ter relacionamentos positivos com os amigos em comparação às participantes que não seguiam o catolicismo, o qual se constitui fator que interfere negativamente nas relações de amizade. Muitas instituições religiosas formam grupos e espaços para jovens, caracterizados por serem locais de agregação e interação social. Dentre estas várias são comunidades católicas existentes no Brasil como a Shalom e Novo Maná, entre outras, as quais têm como principal peculiaridade a juventude de seus membros, tendo sido criadas para jovens ou por jovens 41 .

Entretanto, o declínio do número de seguidores do catolicismo no Brasil, aliado ao crescimento de grupos evangélicos e ao aumento dos indivíduos que se declaram "sem religião", produz mudanças na apresentação social das religiões, especialmente entre os jovens 42 . Estudos mostram que o percentual de jovens que se declaram "sem religião" possui a tendência a ser sempre maior do que o encontrado no resto da população 41,43 . É nessa faixa-etária que aumenta a pos- sibilidade de se declarar "sem religião", contudo, sem abrir mão da fé, ou seja, "ser religioso sem religião" 41. Além disso, jovens que se declaram católicos são menos praticantes da sua religião do que em outros grupos etários 41,43. Na perspectiva de que esta é uma temática pouco explorada entre jovens, principalmente sobre sua repercussão nas decisões de saúde e na própria vida dos jovens, sugere-se que estudos aprofundados sejam desenvolvidos com amostras mais representativas das demais religiões.

\section{Conclusão}

Nossos achados sugerem que políticas públicas de saúde reprodutiva devem ser desenvolvidas para que seja estimulado o fortalecimento do vínculo entre a jovem mãe e as pessoas que com ela convivem. Tais políticas devem ser voltadas não somente para a jovem mãe, mas também devem incluir ações para as pessoas próximas a ela, principalmente o companheiro, os amigos e a mãe. Para tanto, os profissionais de saúde possuem papel essencial na abordagem da importância do apoio social e suporte emocional à jovem, tanto no momento da descoberta da gravidez, quanto após esta, com vistas a evitar repercussões físicas e psicológicas negativas a ela e seu filho. Além disso, visto que o fato da jovem não estudar mostrou-se como fator que interfere negativamente no relacionamento com os seus amigos, cabe reiterar a importância da jovem manter-se estudando após a gestação. 


\section{Resumen}

El objetivo fue analizar los factores que intervienen en las relaciones de jóvenes durante el posparto. Se trata de un estudio transversal con 464 jóvenes de Teresina, Piauí, Brasil, que completaron un embarazo en el primer trimestre de 2006 en seis hospitales de la ciudad. Los datos fueron recogidos entre mayo y diciembre de 2008, después de la identificación de las jóvenes en los registros de maternidad. El análisis multivariado se realizó mediante regresión logística multinomial. Las jóvenes con lazos matrimoniales fueron un $80 \%$ menos propensas a tener relaciones negativas con su cónyuge. Las participantes con edades entre 20 y 22 años estaban relacionadas 2,4 veces mejor con la madre, que las personas de 17-19 años. Las jóvenes que no estudiaban tenían un 97\% más probabilidades de cambios negativos en las relaciones de amistad y, en los católicos, era un $50 \%$ menos probable que hubieran empeorado sus relaciones de amistad después del parto. Se requieren acciones de orientación a las personas que viven con madres jóvenes sobre la importancia del apoyo en este momento de la vida, especialmente, la pareja y la madre, para que la animen a seguir estudiando.

Embarazo; Adolescente; Ralaciones Familiares; Apoyo Social; Matrimonio

\section{Referências}

1. Gomes KRO, Speizer IS, Gomes FM, Oliveira DC, Moura LN. Who are the pregnant adolescents in the poorest state capital of Brazil? Public Health Nurs 2008; 25:319-26.

2. Sousa MCR, Gomes KRO. Conhecimento objetivo e percebido sobre contraceptivos hormonais orais entre adolescentes com antecedentes gestacionais. Cad Saúde Pública 2009; 25:645-54.

3. Rangel DLO, Queiroz ABA. A representação social das adolescentes sobre a gravidez nesta etapa da vida. Esc Anna Nery Rev Enferm 2008; 12:780-8.

4. Ximenes-Neto FRG, Dias MSA, Rocha J, Cunha CKO. Gravidez na adolescência: motivos e percepções de adolescentes. Rev Bras Enferm 2007; 60:279-85.

\section{Colaboradores}

T. A. Maranhão contribuiu substancialmente para a análise e interpretação dos dados e aprovação final da versão a ser publicada. K. R. O. Gomes contribuiu substancialmente para a concepção do projeto, análise e interpretação dos dados e aprovação final da versão a ser publicada. J. M. N. Silva contribuiu substancialmente para a análise e interpretação dos dados e aprovação final da versão a ser publicada.

\section{Agradecimentos}

Ao CNPq e à UFPI.
5. Correia DS, Cavalcante JCC, Egito ST, Maia EMC. Prática do abortamento entre adolescentes: um estudo em dez escolas de Maceió (AL, Brasil). Ciênc Saúde Coletiva. 2011; 16:2469-76.

6. Maranhão TA, Vieira TS, Monteiro CFS. Violência contra adolescentes grávidas: uma revisão integrativa. Universitas: Ciências Saúde 2012; 10:41-9.

7. Cox JE, Buman M, Valenzuela J, Joseph NP, Mitchell A, Woods ER. Depression, parenting attributes, and social support among adolescent mothers attending a Teen Tot Program. J Pediatr Adolesc Gynecol 2008; 21:275-81.

8. Andrade G, Vaistman J. Apoio social e redes: conectando solidariedade e saúde. Ciênc Saúde Coletiva 2002; 7:925-34. 
9. Schwartz T, Vieira R, Geib LTC. Apoio social a gestantes adolescentes: desvelando percepções. Ciênc Saúde Coletiva 2011; 16:2575-85.

10. Gee CB, Rhodes JE. A social support and social strain measure for minority adolescent mothers: a confirmatory factor analytic study. Child Care Health Dev 2007; 34:87-97.

11. Sotto-Mayor IMB, Piccinini CA. Relacionamento conjugal e depressão materna. Psico (Porto Alegre) 2005; 36:135-48.

12. Maia JMD, Williams LCA. Fatores de risco e fatores de proteção ao desenvolvimento infantil: uma revisão da área. Temas Psicol 2005; 13:91-103.

13. Silva IO, Siqueira VHF, Rocha GWF. Educação sexual e gravidez de adolescentes: significados construídos por docentes do curso de formação de professores em uma escola pública do Rio de Janeiro, Brasil. Revista Electrónica de Enseñanza de las Ciencias 2009; 8:216-31.

14. Herrman JW. Adolescent perceptions of teen births. JOGN Nurs 2008; 37:42-50.

15. Nery IS, Mendonça RCM, Gomes IS, Fernandes CAN, Oliveira DC. Reincidência da gravidez em adolescentes de Teresina, PI, Brasil. Rev Bras Enferm 2011; 64:31-7.

16. World Health Organization. Report of WHO technical consultation on birth spacing. Geneva: World Health Organization; 2005.

17. Downing D, Clarck J. Estatística aplicada. São Paulo: Editora Saraiva; 2000.

18. Armitage P. Statistical method in medical research. New York: John Wiley and Sons; 1981.

19. Hamilton LC. Interpreting multinomial logistic regression. Stata Technical Bulletin 1993; 13:24-8

20. Hosmer DW, Lemeshow S. Applied logistic regression. New York: John Wiley \& Sons; 2000.

21. Kutner M, Nachtsheim C, Neter J. Applied linear regression models. Columbus: McGraw-Hill Irwin; 2004.

22. Piccinini CA, Silva MR, Gonçalves TR, Lopes RS, Tudge J. O envolvimento paterno durante a gestação. Psicol Reflex Crit 2004; 17:303-14.

23. Maranhão TA, Gomes KRO, Oliveira DC. Couple and family relationships of adolescents post-pregnancy. Acta Paul Enferm 2012; 25:371-7.

24. Howard KS, Brooks-Gunn J. Relationship supportiveness during the transition to parenting among married and unmarried parents. Parent Sci Pract 2009; 9:123-42.

25. Bassani DG, Surkan PJ, Olinto MT. Inadequate use of prenatal services among Brazilian women: the role of maternal characteristics. Int Perspect Sex Reprod Health 2009; 35:15-20.

26. Alio AP, Mbah AK, Grunsten RA, Salihu HM. Teenage pregnancy and the influence of paternal involvement on fetal outcomes. J Pediatr Adolesc Gynecol 2011; 24:404-9.

27. Piazzalunga CRC, Lamounier JA. A paternidade e sua influência no aleitamento materno. Pediatria (São Paulo) 2009; 31:49-57.
28. Arnold A, Lewis J, Maximovich A, Ickovics J, Kershaw T. Antecedents and consequences of caregiving structure on young mothers and their infants. Matern Child Health J 2011; 15:1037-45.

29. Hoga LAK, Borges ALV, Alvarez REC. Teen pregnancy: values and reactions of family members. Acta Paul Enferm 2009; 22:779-85.

30. Dias AB, Aquino EML. Maternidade e paternidade na adolescência: algumas constatações em três cidades do Brasil. Cad Saúde Pública 2006; 22 : 1447-58.

31. Fernandes AO, Santos-Júnior HPO, Gualda DMR. Adolescent pregnancy: perceptions of mothers of young pregnant women. Acta Paul Enferm 2012; 25:55-60.

32. Ezeah P. Marriage and motherhood: a study of the reproductive health status and needs of married adolescent girls in Nsukka, Nigeria. Journal of Sociology and Social Anthropology 2012; 3:1-6.

33. Zeck W, Bjelic-Radisic V, Haas J, Greimel E. Impact of adolescent pregnancy on the future life of young mothers in terms social, familial, and educational changes. J Adolesc Health 2007; 41:380-8.

34. Hardie JH, Lucas A. Economic factors and relationships quality among young couples: comparing cohabitation and marriage. Journal of Marriage and Family 2010; 72:1141-54.

35. Witter GP, Guimarães EA. Percepções de adolescentes grávidas em relação a seus familiares e parceiros. Psicol Ciênc Prof 2008; 28:548-57.

36. Soares JSF, Lopes MJM. Biografias de gravidez e maternidade na adolescência em assentamentos rurais no Rio Grande do Sul. Rev Esc Enferm USP 2011; 45:802-10.

37. Falcão DV, Salomão NMR. Mães adolescentes de baixa renda: um estudo sobre as relações familiares. Arq Bras Psicol (Rio J. 2003) 2006; 58:11-23.

38. Oliveira NR. Maternidade de adolescentes de periferias sociais e urbanas: algumas análises à luz da psicologia ambiental. Rev Bras Crescimento Desenvolv Hum 2005; 15:69-77.

39. Gomes KRO, Speizer IS. Longitudinal study on self-esteem among recently pregnant Brazilian adolescents. J Reprod Infant Psychol 2010; 28:359-71.

40. Marriel LC, Assis SG, Avanci JQ, Oliveira RVC. Violência escolar e auto-estima de adolescentes. Cadernos de Pesquisa 2006; 36:35-50.

41. Mariz CL. Comunidades de vida no Espírito Santo: juventude e religião. Tempo Social: Revista de Sociologia da USP 2005; 17:253-73.

42. Novaes R. Os jovens "sem religião": ventos secularizantes, "espírito de época" e novos sincretismos. Notas preliminares. Estud Av 2004; 18:321-30.

43. Fernandes SRA. Juventude nas igrejas e fora delas: crenças, percepções da política e (des) vinculações. Revista Tomo 2009; 14:99-126.

Recebido em 05/Fev/2013

Versão final reapresentada em 23/Nov/2013 Aprovado em 28/Nov/2013 